\title{
7-T MRI for brain virtual autopsy: a proof of concept in comparison to 3-T MRI and CT
}

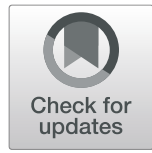

\author{
Dominic Gascho ${ }^{1 *}$ (D), Niklaus Zoelch ${ }^{1,2}$, Stefan Sommer ${ }^{3,4}$, Carlo Tappero ${ }^{1,5}$, Michael J. Thali ${ }^{1}$ and \\ Eva Deininger-Czermak ${ }^{1,6}$
}

\begin{abstract}
The detection and assessment of cerebral lesions and traumatic brain injuries are of particular interest in forensic investigations in order to differentiate between natural and traumatic deaths and to reconstruct the course of events in case of traumatic deaths. For this purpose, computed tomography $(\mathrm{CT})$ and magnetic resonance imaging (MRI) are applied to supplement autopsy (traumatic death) or to supplant autopsy (natural deaths). This approach is termed "virtual autopsy." The value of this approach increases as more microlesions and traumatic brain injuries are detected and assessed. Focusing on these findings, this article describes the examination of two decedents using $\mathrm{CT}$, 3-T, and 7-T MRI. The main question asked was whether there is a benefit in using 7-T over 3-T MRI. To answer this question, the 3-T and 7-T images were graded regarding the detectability and the assessability of coup/ contrecoup injuries and microlesions using 3-point Likert scales. While CT missed these findings, they were detectable on 3-T and 7-T MRI. However, the 3-T images appeared blurry in direct comparison with the 7-T images; thus, the detectability and assessability of small findings were hampered on 3-T MRI. The potential benefit of 7-T over 3-T MRI is discussed.
\end{abstract}

Keywords: Autopsy, Brain injuries (traumatic), Contrecoup injury, Magnetic resonance imaging, Tomography (x-ray, computed)

\section{Key points}

- Brain virtual autopsy by computed tomography (CT) or magnetic resonance imaging (MRI) is an emerging approach in forensic medicine.

- In two decedents, CT missed brain coup/contrecoup injuries and microlesions.

- These findings were detected using 3-T and 7-T MRI but their detection and assessment are hampered at $3 \mathrm{~T}$.

- 7-T brain MRI could be able to determine the absence of shearing brain injuries.

\footnotetext{
* Correspondence: dominic.gascho@irm.uzh.ch

'Department of Forensic Medicine and Imaging, Institute of Forensic Medicine, University of Zurich, Winterthurerstrasse 190/52, CH-8057 Zurich, Switzerland

Full list of author information is available at the end of the article
}

\section{Background}

The term "virtual autopsy" describes the use of imaging technologies as a supplement or alternative to traditional autopsy. For this approach, postmortem magnetic resonance imaging (MRI) has been applied for the radiologic assessment of cerebral tissue [1]. The detection and assessment of traumatic brain injuries and small cerebral lesions can be of particular interest in forensic investigations for differentiating between traumatic and nontraumatic origins of cerebral haemorrhages.

During a traumatic event, the application of different forces to the head can result in characteristic alterations such as shearing or coup and contrecoup injuries [2,3]. Shearing injuries accrue via acceleration-deceleration or rotational acceleration mechanisms of force, resulting in axonal damage $[4,5]$. Coup/contrecoup injuries describe tissue damaged by bruising of the brain directly related 
to the trauma at the site of impact (coup injury) or at the opposite side when the brain hits the skull (contrecoup injury) [6]. The identification of coup/contrecoup injuries can provide information about the direction of the traumatic impact. Contrecoup injuries are usually more pronounced than coup injuries and occur on the opposite side of the impact [6]. In contrast, nontraumatic haemorrhages are usually caused by underlying diseases, such as hypertension or amyloidosis, which are frequently accompanied by microhaemorrhages (also referred to as microbleeds) and small ischaemic lesions (microinfarcts) $[7,8]$. The detection of such microlesions using MRI is highly dependent on the spatial resolution of the images; consequently, the sensitivity for microlesions was first increased by switching from 1.5- $\mathrm{T}$ to $3-\mathrm{T}$ [9] and from 3-T to 7-T MRI [10]. However, a higher magnetic field strength is unfortunately also accompanied by increased inhomogeneities in the main magnetic field $\left(B_{0}\right)$ as well as in the transmit and receive fields $\left(B_{1}\right)$ [11]. These inhomogeneities can negatively affect the image signal and contrast, especially at the periphery of the measured object.

Considering the benefits and drawbacks of 7-T over 1.5-T and 3-T MRI, we deemed it relevant to assess the application of postmortem 7-T MRI for the assessment of traumatic and nontraumatic origins of cerebral haemorrhages. To date, the use of noninvasive postmortem 7-T MRI has only been evaluated for fetal virtual autopsy or radiologic wound ballistics in decedents $[12,13]$. In this article, we present two decedents with cerebral haemorrhages due to a traumatic event or a natural cause who underwent noninvasive postmortem computed tomography (CT), 3-T, and 7-T MRI for forensic purposes. The focus of this article is the detectability and assessability of coup/contrecoup injuries and microlesions.

\section{Methods}

The responsible ethics committee waived ethical approval, as all examinations were performed as part of forensic judicial investigations.

The first case was a 92-year-old woman who was found at the bottom of a staircase. The second case was a 68-year-old man who was found in his bathroom lying on the floor. The postmortem intervals were 14-16 h (case 1) and 26-30 h (case 2) when postmortem imaging was performed. Before MRI, the decedents underwent a routine CT examination using a 128-slice scanner (Somatom Definition Flash, Siemens Healtheeners, Erlangen, Germany) [14]. The parameters of the postmortem head and neck scan were as follows: tube voltage $120 \mathrm{kVp}$; tube current 1,000 mAs; slice thickness $0.6 \mathrm{~mm}$; kernels $\mathrm{H} 60$ and $\mathrm{H} 31$; and field of view $\leq 300 \mathrm{~mm}$, adjusted to the head.

After the CT scan, the decedents were examined using a 3-T MRI scanner (Achieva 3.0 T TX, Philips Healthcare, Best, The Netherlands) and a 7-T MRI scanner (Magnetom Terra, Siemens Healthneers, Erlangen, Germany). For comparison with CT, a 7-T three-dimensional gradient-echo sequence (repetition time $4.2 \mathrm{~ms}$, echo time $1.5 \mathrm{~ms}$, voxel size $0.20 \mathrm{~mm} \times$ $0.20 \mathrm{~mm} \times 0.50 \mathrm{~mm}$, scan time $6: 21 \mathrm{~min}: \mathrm{s})$ was performed to visualise any osseous injuries. For the comparison of coup/contrecoup injuries and microlesions detected at 3-T and 7-T MRI, T1-weighted, T2weighted, and susceptibility-weighted sequences were obtained (Table 1). Imaging was performed while the decedents were lying in the body bag.

The assessability (related to the image quality) and the detectability of the coup/contrecoup injuries and microlesions were graded using 3-point Likert scales. For assessability, images were assigned score 1 (poor image quality, blurred images), score 2 (moderate image

Table 1 3-T and 7-T protocols and radiologic assessment of coup/contrecoup injuries and microlesions

\begin{tabular}{|c|c|c|c|c|c|c|}
\hline \multirow[t]{2}{*}{ Sequence } & $3 \mathrm{~T}$ & $7 \mathrm{~T}$ & $3 T$ & $7 \mathrm{~T}$ & $3 T$ & $7 \mathrm{~T}$ \\
\hline & T1-w. TFE & T1-w. MP2RAGE & T2-w. TSE SPAIR & T2-w. SPACE & VenBOLD & SWI \\
\hline Repetition time (ms) & 9.4 & 4,500 & 1,500 & 4,000 & 18 & 21 \\
\hline Echo time (ms) & 4.6 & 2 & 230 & 118 & 26 & 14 \\
\hline Voxel size* & $1.00 \times 1.00 \times 2.00$ & $0.65 \times 0.65 \times 0.63$ & $0.80 \times 0.80 \times 1.60$ & $0.71 \times 0.71 \times 0.67$ & $0.80 \times 0.80 \times 1.60$ & $0.12 \times 0.12 \times 1.50$ \\
\hline Slice orientation & Sagittal & Sagittal & Transversal & Sagittal & Transversal & Transversal \\
\hline Scan time (min:s) & 08:50 & 10:45 & 06:00 & 05:39 & $06: 21$ & 10:40 \\
\hline Coup injury & $1-$ & $2+$ & $1+$ & $3++$ & $1+$ & $3++$ \\
\hline Contercoup injury & $1-$ & $2+$ & $1+$ & $3++$ & $1+$ & $3++$ \\
\hline Microinfarct & $1-$ & $2-$ & $1+$ & $2++$ & $1-$ & $3-$ \\
\hline Microhaemorrhage & $1-$ & $2-$ & $1+$ & $2++$ & $1+$ & $3+$ \\
\hline
\end{tabular}

MP2RAGE Magnetisation prepared 2 rapid gradient echoes, SPACE Sampling perfection with application-optimised contrasts by using different flip angle evolutions, SPAIR Spectral attenuated inversion recovery, SWI Susceptibility-weighted imaging, TFE Turbo field echo, TSE Turbo spin echo, VenBOLD Venous blood oxygen level dependent

*Frequency direction $\times$ phase direction $\times$ slice thickness 
quality), or score 3 (good image quality, sharp images). For lesion detectability, images were scored "-" (lesions not detected or inconclusive), "+" (lesions detected), or "++" (lesions highlighted or more accurately depicted than on comparative images). Grading was conducted by a board-certified radiologist with 13 years of professional experience.

\section{Results}

The grading of the coup/contrecoup injuries and microlesions are summarised in Table 1.

\section{Case 1 (traumatic injuries)}

On CT and MRI, the skull showed a disruption of the surface and subcutaneous haemorrhages and a segmental bone fracture of the left parietal bone, which was identified as the site of the impact (Fig. 1). Furthermore, subarachnoid, subdural, and brainstem haemorrhages were visible on CT as well as on MRI.

Only MRI allowed the detection of discrete parenchymal defects in the left parietal and temporal cortex, which were described as coup injuries. Corresponding contrecoup injuries were detected on the opposite side in the right parietal and temporal cortex on MRI (Fig. 2). These subtle parenchymal defects with intraparenchymal haemorrhages were $<2 \mathrm{~mm}$ in size. The coup/contrecoup injuries were highlighted on 7-T MRI using the T2-weighted sequence and the susceptibility-weighted sequence. The clear delineation of the subtle parenchymal defects on 7-T MRI facilitated the identification of the contrecoup injuries and enabled us to exclude the presence of shearing injuries, as no shear strain or signs of physical disruptions along the white and grey matter junction were detected. On 3-T MRI, the subtle parenchymal defects appeared blurrier than those on 7-T MRI (Fig. 2), and shearing injuries could not be excluded.

The radiologic findings were confirmed by autopsy. The cause of death was attributed to a brainstem haemorrhage. The manner of death was determined to be unnatural (accidental death) because of the parietal bone fracture and coup and contrecoup injuries.

\section{Case 2 (nontraumatic injuries)}

An intracerebral haemorrhage in the left temporal lobe was diagnosed at CT and MRI (Fig. 3a, b). The assessment of the surrounding tissue was impeded on CT scans by an accompanying brain edema. On MRI, the haemorrhage was clearly delineated, although the 3-T images appeared blurrier than the 7-T images. The 7- $\mathrm{T}$ T2-weighted images, however, demonstrated visible signal inhomogeneity on the lateral left side adjacent to the haemorrhage (Fig. 3a).

Only MRI allowed the detection of a small T2hyperintense ischaemic microinfarct next to the head of the caudate nucleus in the left hemisphere (Fig. 3c, d). On 7-T T2-weighted images, this white matter lesion was delineated with moderate image quality compared with the blurriness of the 3-T images. The diameter of the microinfarct differed between 3-T and 7-T T2-

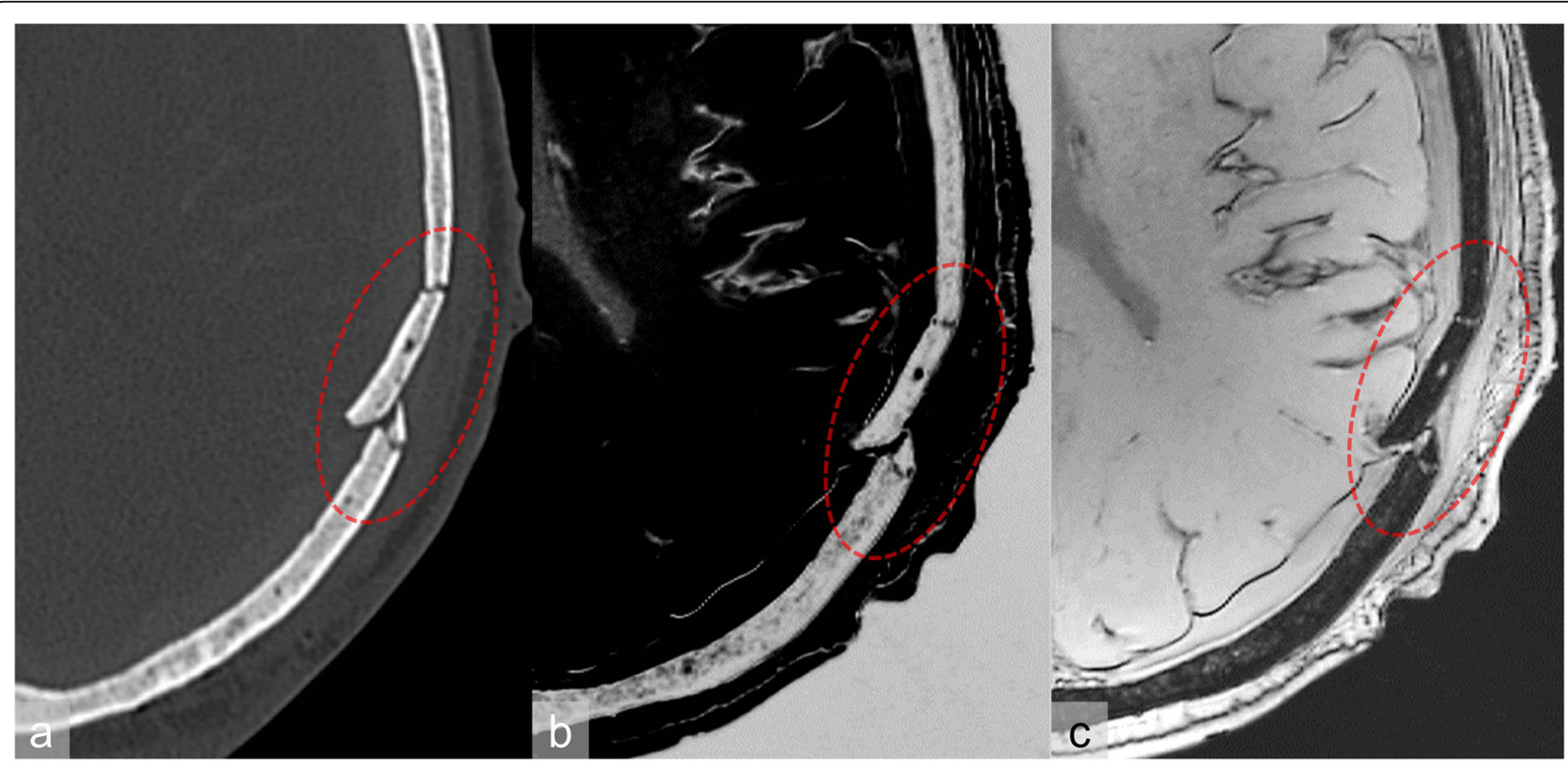

Fig. 1 Case 1. Computed tomography (a) and 7-T magnetic resonance imaging (b: spoiled gradient-echo sequence, contrast inverted; c: spoiled gradient-echo sequence) demonstrate a fracture (red circle) of the left parietal bone. The fracture was very well delineated thanks to the high spatial resolution of the 7-T spoiled gradient-echo sequence 


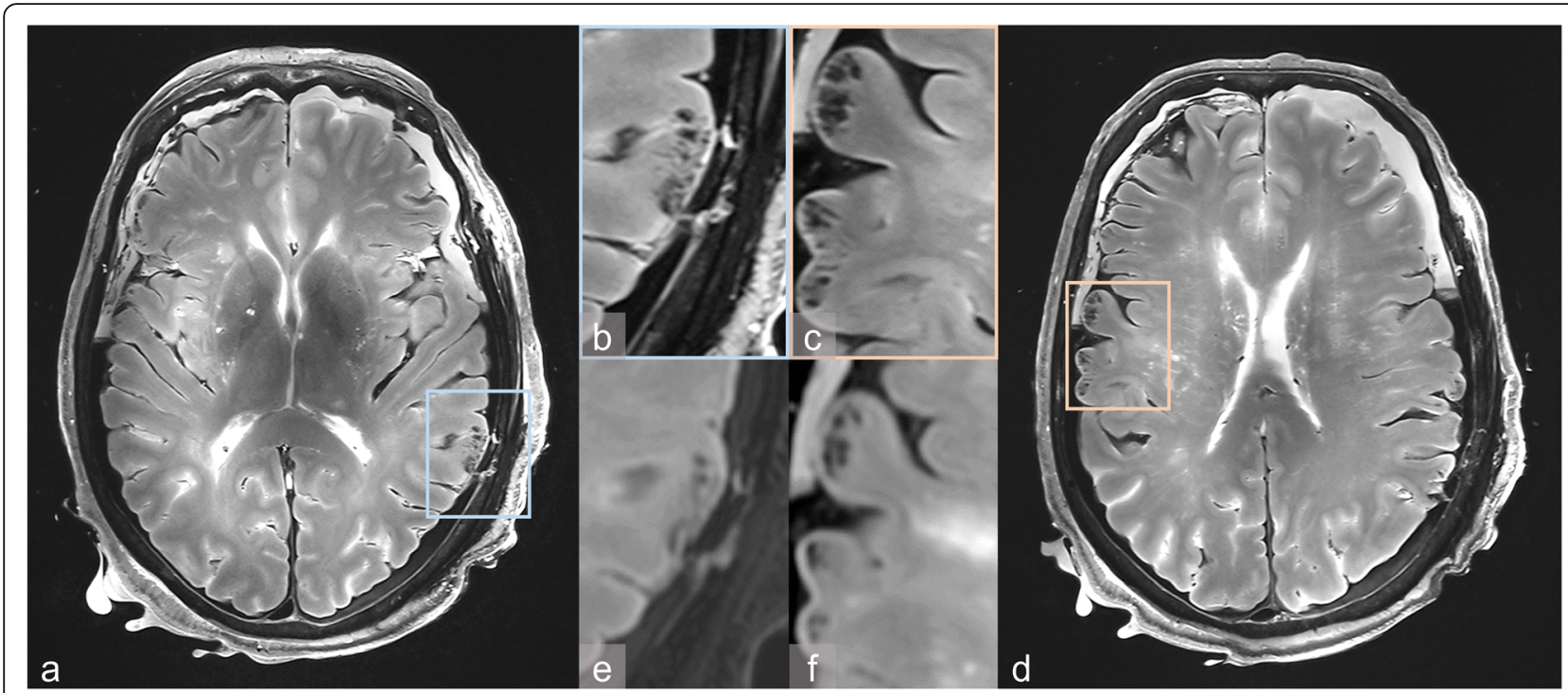

Fig. $\mathbf{2}$ a-d Case 1. 7-TT2-weighted images demonstrate coup injuries (a, b) and contrecoup injuries (c, d). 3-TT2-weighted images appear blurred for both coup injuries (e) and contrecoup injuries (f)

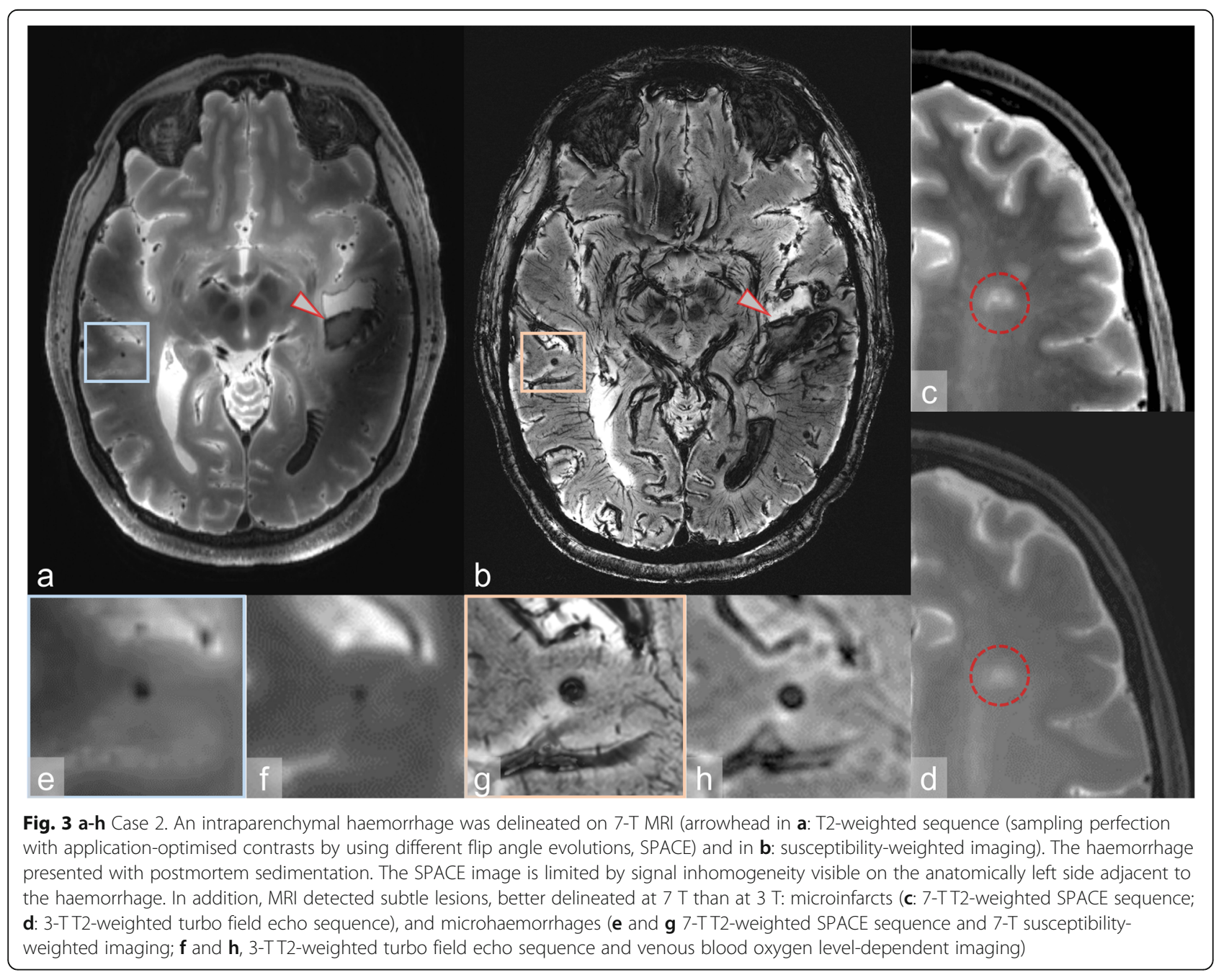


weighted images: the maximum diameter was $8.2 \mathrm{~mm}$ at $3 \mathrm{~T}$ and $9.6 \mathrm{~mm}$ at $7 \mathrm{~T}$. The same applied for multiple microhaemorrhages (diameter $<1 \mathrm{~mm}$ ) that were located in the right parietal and temporal lobe areas, which were visualised smaller on 3-T than on 7-T T2-weighted images (Fig. 3e, f). These differences in size were not observed on the susceptibility-weighted images. However, microhaemorrhages appeared darker on the sharp 7-T images than on the blurry 3-T images (Fig. 3g, h).

The detection of ischaemic microinfarcts and multiple microhaemorrhages, together with the absence of bone fractures, bone edema, shearing injuries, or coup/contrecoup injuries, allowed the determination of the large intracerebral haemorrhage as a naturally caused injury. Accordingly, the manner of death was determined to be natural; therefore, the state attorney waived the need for an additional autopsy.

\section{Discussion}

The MRI examinations enabled the visualisation of coup and contrecoup injuries (case 1) and microlesions (case 2) that were not identifiable on CT scans. Compared with 3-T MRI, 7-T MRI improved the assessability of the extent of the coup and contrecoup injuries and facilitated the detection of microlesions.

Overall, 3-T images appeared blurrier than the 7-T images, as expected. In fact, spin polarisation is increased for 7-T units, compared with that of the widely used 1.5-T and 3-T units, which in turn leads to a stronger signal and thus an increased signal-to-noise ratio [15]. The increased signal-to-noise ratio directly improves the image quality and can be used to improve spatial resolution or to shorten the scan time for the same spatial resolution [16]. Due to the roughly twofold lower signal-to-noise ratio at 3-T than at 7-T, the scan time would need to be at least four times longer to achieve similar image quality on 3-T MRI with the same spatial resolution. A drawback of 7-T MRI is the greater signal inhomogeneity due to the transmit $B_{1}$ inhomogeneity. This phenomenon was illustrated by case 2 . To improve the image quality in the presence of inhomogeneous magnetic fields, various approaches have been investigated regarding acquisition (e.g., the use of multichannel transmit arrays $[17,18]$ ) or postprocessing (e.g., improved image reconstruction algorithms [19]).

The use of sharp thin-sliced 7-T images with high sensitivity to metals is appreciated for the radiologic diagnosis of subtle lesions and iron accumulation in specific brain diseases [20-24]. Especially for the early diagnosis of multiple sclerosis, 7-T MRI can be of particular importance, since 7-T MRI improves the ability to detect smaller and earlier multiple sclerosis lesions and 7-T MRI allows a more accurate characterisation of these lesions for discriminating multiple sclerosis from other brain diseases compared to 1.5-T and 3-T MRI [25].

According to our observations, 7-T MRI can facilitate the classification of the origin of cerebral haemorrhages as either traumatic or natural. In case 1, the detection of coup/contrecoup injuries allowed the description of the impact, leading to the diagnosis of an accelerationdeceleration injury. The exclusion of shearing injuries was facilitated on 7-T images, which can be considered an advantage over 3-T MRI and may be of special value in the assessment of child abuse [26]. The use of a threedimensional gradient-echo sequence at $7 \mathrm{~T}$ provided a detailed visualisation of the parietal bone fracture. As a consequence, this approach may be appropriate for delineating cranial fractures on MRI. For the same purpose, dedicated sequences can be applied at $3 \mathrm{~T}[27,28]$. An accurate depiction of cranial fractures on MRI can aid in the assessment of related soft tissue injuries.

In case 2, 7-T MRI showed a slight advantage over 3-T MRI in the classification of discrete lesions, in accordance with previous research [29]. The 7-T T2-weighted images not only allowed a clear distinction of the microinfarct from the surrounding tissue but also depicted the rather precise extent of this microlesion, which is due to the small isotropic voxels of the 7-T sequence. On T2weighted images, the microhaemorrhages were larger in diameter at $7 \mathrm{~T}$ than at $3 \mathrm{~T}$, in accordance with the literature $[30,31]$. On susceptibility-weighted images, microhaemorrhages were highlighted at both $3 \mathrm{~T}$ and $7 \mathrm{~T}$, due to susceptibility effects of paramagnetic deoxygenated blood [32]. A voxel size of $1.5 \mathrm{~mm}$ (7-T MRI) or $1.6 \mathrm{~mm}$ (3-T MRI) in the slice direction still enabled the clear visualisation of these subtle lesions on susceptibilityweighted images. An increase in the diameter of the microhaemorrhages at $7 \mathrm{~T}$ over $3 \mathrm{~T}$, as observed on the T2-weighted images, was not observed on the susceptibility-weighted images. Likewise, only a small increase in the diameter of the microhaemorrhages has been reported between $1.5-\mathrm{T}$ and $3-\mathrm{T}$ MRI in the literature [33].

In conclusion, all distinctive and subtle findings were detectable on both 3-T and 7-T MRI, but the 7-T images provided higher detectability and assessability of traumatic brain injuries and microlesions. Certainly, the relevance of this advantage should be weighed against the practicability of 7-T MRI, which is dependent on several factors, in particular the accessibility to a $7-\mathrm{T}$ scanner. Notwithstanding this limitation, further studies on 7-T MRI for various diagnostic purposes are appreciated.

\section{Abbreviations}

$C T$ : Computed tomography; MRI: Magnetic resonance imaging; SPACE: Sampling perfection with application-optimised contrasts by using different flip angle evolutions 


\section{Acknowledgements}

The authors would like to thank Daniel Nanz from the Swiss Center for Musculoskeletal Imaging (SCMI) for endorsing the collaboration between the SCMI and the Institute of Forensic Medicine in this field of research. The authors express their gratitude to Emma Louise Kessler for her donation to Zurich Institute of Forensic Medicine, University of Zurich, Switzerland.

\section{Statement of authorship}

We hereby declare that we are the sole authors of this original article and that we have not used any sources other than those identified as references. We further declare that we have not submitted this original article to any other journal.

\section{Authors' contributions}

DG. wrote the article. ED-C and NZ. participated in writing the original draft of the manuscript. ED-C. and DG. selected the images and DG. created the figures. ED-C, Nz, SS, and CT reviewed the final manuscript. MJT. provided the technical equipment. All authors approved the submitted version of the manuscript.

\section{Funding}

The authors state that this work has not received any funding.

\section{Ethics approval and consent to participate}

This study was performed with human cadavers. Ethical approval was waived by the responsible ethics committee of the Canton of Zurich (waiver number: 2015-0686). This article does not contain any studies with (living) human participants.

\section{Consent for publication}

Not applicable.

\section{Competing interests}

None of the authors has a real or perceived conflict of interest in any of the material that is presented in this manuscript. However, one coauthor of this manuscript is affiliated with Siemens Healthcare. This coauthor was not involved in the radiological assessments but instead approved the technical description.

\section{Author details}

${ }^{1}$ Department of Forensic Medicine and Imaging, Institute of Forensic Medicine, University of Zurich, Winterthurerstrasse 190/52, CH-8057 Zurich, Switzerland. ${ }^{2}$ Department of Psychiatry, Psychotherapy and Psychosomatics, Hospital of Psychiatry, University of Zurich, Zurich, Switzerland. ${ }^{3}$ Siemens Healthcare AG, Zurich, Switzerland. ${ }^{4}$ Swiss Center for Musculoskeletal Imaging (SCMI), Balgrist Campus AG, Zurich, Switzerland. ${ }^{5}$ Department of Radiology, Hôpital Fribourgeois, Villars-sur-Glâne, Switzerland. ${ }^{6}$ Institute of Diagnostic and Interventional Radiology, University Hospital Zurich, Zurich, Switzerland.

\section{Received: 9 September 2020 Accepted: 26 November 2020}

\section{Published online: 14 January 202}

\section{References}

1. Thali MJ, Yen K, Schweitzer W et al (2003) Virtopsy, a new imaging horizon in forensic pathology: virtual autopsy by postmortem multislice computed tomography (MSCT) and magnetic resonance imaging (MRI) — a feasibility study. J Forensic Sci 48:386-403. https://doi.org/10.1520/JFS2002166

2. Courville CB (1942) Coup-contrecoup mechanism of craniocerebral injuries: some observations. Arch Surg 45:19-43. https://doi.org/10.1001/archsurg. 1942.01220010022002

3. Peerless SJ, Rewcastle NB (1967) Shear injuries of the brain. Can Med Assoc J 96:577

4. Strich SJ (1956) Diffuse degeneration of the cerebral white matter in severe dementia following head injury. J Neurol Neurosurg Psychiatry 19:163-185. https://doi.org/10.1136/jnnp.19.3.163

5. Rush B (2011) Shearing injury, shear strain. In: Kreutzer JS, DeLuca J, Caplan B (eds) Encyclopedia of Clinical Neuropsychology. Springer, New York

6. Bauer M, Polzin S, Patzelt D (2004) The use of clinical CCT images in the forensic examination of closed head injuries. J Clin Forensic Med 11:65-70. https://doi.org/10.1016/j.jcfm.2003.10.003
7. Viswanathan A, Chabriat H (2006) Cerebral microhemorrhage. Stroke 37: 550-555. https://doi.org/10.1161/01.STR.0000199847.96188.12

8. Van Veluw SJ, Jolink WM, Hendrikse J et al (2014) Cortical microinfarcts on $7 \mathrm{~T} \mathrm{MRI} \mathrm{in} \mathrm{patients} \mathrm{with} \mathrm{spontaneous} \mathrm{intracerebral} \mathrm{hemorrhage.} \mathrm{J}$ Cereb Blood Flow Metab 34:1104-1106. https://doi.org/10.1038/jcbfm. 2014.73

9. Scheid R, Ott DV, Roth H, Schroeter ML, von Cramon DY (2007) Comparative magnetic resonance imaging at 1.5 and 3 Tesla for the evaluation of traumatic microbleeds. J Neurotrauma 24:1811-1816. https://doi.org/10. 1089/neu.2007.0382

10. Bian W, Hess CP, Chang SM, Nelson SJ, Lupo JM (2014) Susceptibilityweighted MR imaging of radiation therapy-induced cerebral microbleeds in patients with glioma: a comparison between $3 \mathrm{~T}$ and $7 \mathrm{~T}$. Neuroradiology 56:91-96. https://doi.org/10.1007/s00234-013-1297-8

11. Uwano I, Kudo K, Yamashita F et al (2014) Intensity inhomogeneity correction for magnetic resonance imaging of human brain at $7 \mathrm{~T}$. Med Phys 41:022302. https://doi.org/10.1118/1.4860954

12. Staicu A, Albu C, Popa-Stanila R et al (2019) Potential clinical benefits and limitations of fetal virtopsy using high-field MRI at 7 Tesla versus stereomicroscopic autopsy to assess first trimester fetuses. Prenat Diagn 39: 505-518. https://doi.org/10.1002/pd.5457

13. Gascho D, Deininger-Czermak E, Zoelch N et al (2020) Noninvasive 7 tesla MRI of fatal craniocerebral gunshots - a glance into the future of radiologic wound ballistics. Forensic Sci Med Pathol. https://doi.org/10.1007/s12024020-00300-w

14. Gascho D, Thali MJ, Niemann T (2018) Post-mortem computed tomography: technical principles and recommended parameter settings for highresolution imaging. Med Sci Law 58:70-82. https://doi.org/10.1177/ 0025802417747167

15. Pohmann $R$, Speck $O$, Scheffler K (2016) Signal-to-noise ratio and MR tissue parameters in human brain imaging at 3, 7, and 9.4 tesla using current receive coil arrays: SNR at 9.4 T. Magn Reson Med 75:801-809. https://doi. org/10.1002/mrm.25677

16. Wald LL (2012) The future of acquisition speed, coverage, sensitivity, and resolution. Neuroimage 62:1221-1229. https://doi.org/10.1016/j.neuroimage. 2012.02.077

17. Orzada S, Bitz AK, Johst S et al (2017) Analysis of an integrated 8-channel Tx/Rx body array for use as a body coil in 7-Tesla MRI. Front Phys 5:17. https://doi.org/10.3389/fphy.2017.00017

18. Kraff O, Fischer A, Nagel AM, Mönninghoff C, Ladd ME (2015) MRI at 7 tesla and above: demonstrated and potential capabilities. J Magn Reson Imaging 41:13-33. https://doi.org/10.1002/jmri.24573

19. George MM, Kalaivani S (2019) Retrospective correction of intensity inhomogeneity with sparsity constraints in transform-domain: application to brain MRI. Magn Reson Imaging 61:207-223. https://doi.org/10.1016/..mri.2019.04.011

20. Hammond KE, Metcalf M, Carvajal L et al (2008) Quantitative in vivo magnetic resonance imaging of multiple sclerosis at 7 Tesla with sensitivity to iron. Ann Neurol 64:707-713. https://doi.org/10.1002/ana.21582

21. Tallantyre EC, Morgan PS, Dixon JE et al (2010) 3 Tesla and 7 Tesla MRI of multiple sclerosis cortical lesions. J Magn Reson Imaging 32:971-977. https://doi.org/10.1002/jmri.22115

22. Kwan JY, Jeong SY, Gelderen PV et al (2012) Iron accumulation in deep cortical layers accounts for MRI signal abnormalities in ALS: correlating 7 Tesla MRI and pathology. PLos One 7:e35241. https://doi.org/10.1371/ journal.pone.0035241

23. Dusek P, Bahn E, Litwin T et al (2017) Brain iron accumulation in Wilson disease: a post mortem 7 Tesla MRI - histopathological study. Neuropathol Appl Neurobiol 43:514-532. https://doi.org/10.1111/nan.12341

24. Cocozza S, Cosottini M, Signori A et al (2020) A clinically feasible 7-Tesla protocol for the identification of cortical lesions in multiple sclerosis. Eur Radiol 30:4586-4594. https://doi.org/10.1007/s00330-020-06803-y

25. Bruschi N, Boffa G, Inglese M (2020) Ultra-high-field 7-T MRI in multiple sclerosis and other demyelinating diseases: from pathology to clinical practice. Eur Radiol Exp 4:59. https://doi.org/10.1186/s41747-020-00186-x

26. Hart BL, Dudley MH, Zumwalt RE (1996) Postmortem cranial MRI and autopsy correlation in suspected child abuse. Am J Forensic Med Pathol 17 217-224. https://doi.org/10.1097/00000433-199609000-00008

27. Eley KA, Watt-Smith SR, Golding SJ (2012) "Black bone" MRI: a potential alternative to $C T$ when imaging the head and neck: report of eight clinical cases and review of the Oxford experience. Br J Radiol 85:1457-1464. https://doi.org/10.1259/bjr/16830245 
28. Gascho D, Zoelch N, Tappero C et al (2020) FRACTURE MRl: optimized 3D multi-echo in-phase sequence for bone damage assessment in craniocerebral gunshot injuries. Diagn Interv Imaging. 101:611-615. https://doi.org/10.1016/.j.dii.2020.02.010

29. Springer E, Dymerska B, Cardoso PL et al (2016) Comparison of routine brain imaging at $3 \mathrm{~T}$ and 7 T. Invest Radiol 51:469-482. https://doi.org/10.1097/RLI. 0000000000000256

30. Smith EE, Schneider JA, Wardlaw JM, Greenberg SM (2012) Cerebral microinfarcts: the invisible lesions. Lancet Neurol 11:272-282. https://doi. org/10.1016/S1474-4422(11)70307-6

31. Mulder MJ, Keuken MC, Bazin P-L, Alkemade A, Forstmann BU (2019) Size and shape matter: the impact of voxel geometry on the identification of small nuclei. PLoS One 14:e0215382. https://doi.org/10.1371/journal.pone. 0215382

32. Liu C, Li W, Tong KA, Yeom KW, Kuzminski S (2015) Susceptibility-weighted imaging and quantitative susceptibility mapping in the brain. J Magn Reson Imaging 42:23-41. https://doi.org/10.1002/jmri.24768

33. Nandigam RNK, Viswanathan A, Delgado P et al (2009) MR imaging detection of cerebral microbleeds: effect of susceptibility-weighted imaging section thickness, and field strength. AJNR Am J Neuroradiol 30:338-343. https://doi.org/10.3174/ajnr.A1355

\section{Publisher's Note}

Springer Nature remains neutral with regard to jurisdictional claims in published maps and institutional affiliations.

\section{Submit your manuscript to a SpringerOpen ${ }^{\circ}$ journal and benefit from:}

- Convenient online submission

- Rigorous peer review

- Open access: articles freely available online

High visibility within the field

- Retaining the copyright to your article

Submit your next manuscript at $\boldsymbol{\wedge}$ springeropen.com 